\title{
PROTECTION OF STAINLESS-STEELS AGAINST CORROSION IN SULPHIDIZING ENVIRONMENTS BY Ce OXIDE COATINGS: X-RAY ABSORPTION AND THERMOGRAVIMETRIC STUDIES
}

\section{T. FRANSEN and P.J. GELLINGS}

Laboratory for Inorganic Chemistry and Materials Science, Twente University of Technology, P.O. Box 217, 7500 AE Enschede, The Netherlands

\section{J.C. FUGGLE}

Laboratory for Molecular Spectroscopy, Katholieke Universiteit, Toernooiveld, 6525 ED Nijmegen, The Netherlands

G. VAN DER LAAN

Materials Science Centre, University of Groningen, Nijenborgh 16, 9747 AG Groningen, The Netherlands

and

\section{J.-M. ESTEVA and R.C. KARNATAK}

Laboratoire pour l'Utilization du Rayonnement Electromagnétique, Bâtiment 350, Universitè de Paris, F- 91405 Orsay Cedex, France

Received 30 July 1984; accepted for publication 18 September 1984

In this paper a study is reported concerning ceramic coatings containing cerium oxide, prepared by the sol-gel method, used to protect Incoloy $800 \mathrm{H}$ against sulphidation. When the coating is sintered in air at $850^{\circ} \mathrm{C}$ good protection is obtained. In an X-ray absorption spectroscopic study of the coatings it was observed that the best protective coating contains all cerium as $\mathrm{Ce}^{\mathrm{IV}}$ after pretreatment. After sulphidizing cerium was reduced to $\mathrm{Ce} \mathrm{e}^{\mathrm{III}}$. Possible mechanisms to explain the protective properties are discussed.

\section{Introduction}

Stainless steels give excellent protection against corrosion in oxidizing environments. However, there is an increasing need for materials resistant to the reducing, sulphidizing environments present in the plants for gasification of coal or heavy oils as well as many areas of the (petro)chemical industry. At present many plants in these areas must be based on metallic components with a short lifetime if cooling of the components is not possible [1].

0378-5963/85/\$03.30@ Elsevier Science Publishers B.V. (North-Holland Physics Publishing Division) 
Because of the high temperatures involved coating procedures must rely on metallic or ceramic layers, of which the latter hold most promise. The use of protective "ceramic" layers is quite a recent development even for oxidizing environments [1,4] and until now very little has been done on protection against sulphidation.

For oxidizing environments Ecer et al. [2], found that a very good resistance could be obtained by dipping $\mathrm{Ni}$ - or Fe-base alloys in a slurry of $\mathrm{CeO}_{2}$ in ethanol, followed by drying and sintering in air. Bennett et al. [3]. using the so-called sol-gel method, were also able to obtain a greatly improved oxidation resistance.

The mechanism of this improvement has been suggested to be the adsorption of $\mathrm{Ce}^{4+}$ ions on the grain boundaries of the oxide layer, thus effectively blocking fast diffusion pathways. In addition it was suggested that adsorption of $\mathrm{Ce}$ hindered grain growth, resulting in a better adherence to the substrate due to enhanced plasticity of the oxide [3]. However, there is no direct evidence supporting these mechanisms.

In this paper we show that coating stainless steels with Ce oxide by means of the sol-gel method improves the sulphidation resistance by several orders of magnitude, and that its effectivity depends on the pretreatment of the coated material [4]. In addition we report upon an XAS-study to give some evidence for the mechanism for such protection.

As it is expected that the state of the cerium ions present in the coating plays a significant role it was decided to try to establish this by spectroscopic means. In principle, several spectroscopic methods can be used to distinguish the chemical valence of $\mathrm{Ce}$, including electron and $\mathrm{X}$-ray spectroscopies at the $3 \mathrm{~d}$ and $2 \mathrm{p}$ edges. For the particular problem in hand $\mathrm{X}$-ray absorption at the $3 \mathrm{~d}$ edges in the photoyield mode is most appropriate because of its intermediate probing depth. In electron spectroscopies like ESCA, the inelastic mean free path of the electrons is only about $1 \mathrm{~nm}$. Thus the signal from the ceriated layer is strongly influenced by a miscellaneous layer of hydrocarbons, strongly bound water, and other contaminants which coats any "real" surface and even the Ce contribution to the signals is only characteristic of the extreme surface. Sputtering methods are useful but ambiguous because the sputtering ions damage the sample to a depth comparable to the probing depth of electron spectroscopy. This is not a problem in X-ray absorption in the photoyield mode where the characteristic probing depth is some tens of nanometers.

The principle of this method relies on the fact that the electron photocurrent from a sample is proportional to the number of photons absorbed in the surface layer. If only the elastic (no-loss) photocurrent is detected, then the photocurrent is proportional to the number of photons absorbed within one inelastic mean free pathlength of the surface. It is more usual to collect electrons from the entire photoelectron spectrum including the secondaries. In 
this case the current is proportional to the number of photons absorbed in a surface layer of the order of tens of nanometers thick because even electrons that have been scattered many times, can escape the surface. The characteristic absorption length for soft X-rays, being typically hundreds of nanometers, is long even by comparison with the escape depth of secondary electrons. Consequently, the photoyield spectrum in total yield mode is exactly equivalent to the absorption spectrum in transmission mode. Whilst still not a "bulk" method, X-ray absorption can "see through" surface contamination and thus has potential as a tool for the study of technologically interesting "dirty" samples which has been underexploited until now.

$\mathrm{X}$-ray absorption and emission are well known as quantitative analytical tools, but is less well known that they may also be useful tools for qualitative analysis, e.g., to determine the valence of an element. Ce is a case where XAS should work rather well because of the localized f-electrons. $\mathrm{Ce}^{\mathrm{III}}$ compounds have nominally one $4 \mathrm{f}$-electron, $\mathrm{Ce}^{\mathrm{IV}}$ compounds have nominally none. Hybridization of the f-electrons with the other valence states only slightly changes the simple picture for $\mathrm{Ce}^{\mathrm{III}}$ compounds [5-8]. Thus the $3 \mathrm{~d}$ absorption "edges" have strong peaks which can be interpreted as due to transitions from the initial state to the $3 \mathrm{~d}^{9} 4 \mathrm{f}^{2}$ or $3 \mathrm{~d}^{9} 4 \mathrm{f}^{1}$ final states [4-8]. The spectra themselves contain complicated multiplet and many-body effects whose interpretation is not trivial [5-7], but this does not hinder the use of the spectra as a fingerprint for $\mathrm{Ce}^{\mathrm{III}}$ and $\mathrm{Ce}^{\mathrm{IV}}$. The salient point here is simply that the spectra are distinct and the $3 \mathrm{~d} \rightarrow 4 \mathrm{f}$ transitions are at different energies in $\mathrm{Ce}^{\mathrm{III}}$ and $\mathrm{Ce}^{\mathrm{IV}}$ compounds. For $\mathrm{CeO}_{2}$ the position is more complicated but the spectrum is still quite distinct [9].

\section{Experimental}

\subsection{Material}

The composition of Incoloy $800 \mathrm{H}$ which has been investigated in this work was (in wt \%): $\mathrm{Cr} 19.9$, Ni 31.7, C 0.08, Mn 0.7, Si 0.5, Ti 0.4, Fe balance.

The material was annealed for $1 \mathrm{~h}$ at $1350 \mathrm{~K}$, water quenched, annealed for $1 \mathrm{~h}$ at $1230 \mathrm{~K}$ and water quenched again. Samples of $10 \times 8 \times 3 \mathrm{~mm}^{3}$ were always cut from the stock material with good cooling. The final surface finish was grinding with 500 grit $\mathrm{SiC}$ paper. All test specimens were ultrasonically cleaned with hexane and ethanol prior to coating and/or sulphidation.

\subsection{Preparation of the sols}

Cerium hydroxide $\left(\mathrm{Ce}(\mathrm{OH})_{3}\right)$ was prepared from cerium nitrate, $\mathrm{Ce}\left(\mathrm{NO}_{3}\right)_{3}$. $6 \mathrm{H}_{2} \mathrm{O}$ and $\mathrm{NH}_{4} \mathrm{OH}$. The $\mathrm{Ce}(\mathrm{OH})_{3}$ was stirred in dilute $\mathrm{HNO}_{3}$ at $60^{\circ} \mathrm{C}$, yielding a sol with $\mathrm{pH}=0.3$. 


\subsection{Application of the coatings}

The coatings were applied by immersing (dipping) the test pieces in the sol and withdrawing them from the liquid at a speed of $0.7 \mathrm{~mm} s 1$, followed by drying for $16 \mathrm{~h}$ in air at $20^{\circ} \mathrm{C}$.

\subsection{Pretreatment of coatings}

The ceria deposits were sintered in air or in argon at 1 atm by heating the specimens to $850^{\circ} \mathrm{C}$ at a rate of $30^{\circ} \mathrm{C} \mathrm{h}^{1}$ and directly after reaching the maximum temperature cooling at a rate of $30^{\circ} \mathrm{C} \mathrm{h}-1$ to $20^{\circ} \mathrm{C}$. For comparative purposes non-coated specimens were also included in the test. These were subjected, both without further pretreatment and after $2 \mathrm{~h}$ exposure to $\mathrm{HNO}_{3}$ $(\mathrm{pH}=0.3)$, to the same heat treatment procedure prior to sulphidation.

\subsection{Sulphidation tests}

Thermogravimetric measurements were performed in a Cahn-1000 balance. The test pieces were suspended in the balance which was first flushed for $16 \mathrm{~h}$ with argon at a flow rate of $180 \mathrm{ml} \mathrm{min}{ }^{1}$. Subsequently the temperature was increased. As soon as the desired temperature $\left(550^{\circ} \mathrm{C}\right.$ in this study) was reached a flow of $50 \mathrm{ml} \mathrm{min}{ }^{-1}$ of hydrogen containing $5 \% \mathrm{H}_{2} \mathrm{~S}$ was introduced. This yields a sulphur partial pressure of approximately $10^{2} \mathrm{kPa}$. After exposure all specimens were examined using conventional optical and scanning electron microscopy. In some cases electron microprobe analyses were performed with a JEM200CX electron microscope equipped with an ASID3D and a LINK 860 quantitative EDS analyzer. The spot size was $40 \mathrm{~nm}$ resulting in a lateral resolution of $100-200 \mathrm{~nm}$.

\subsection{X-ray absorption spectroscopy}

The observations were carried out using the background continuum emitted by the Anneau de Collisions d'Orsay (ACO) storage ring at Orsay as a source of synchroton radiation. A double crystal monochromator equipped with beryl single crystals gave a tunable X-ray beam with about $0.37 \mathrm{eV}$ resolution in this energy region [10]. An open channeltron was used as the electron detector. Checks were made on the light flux using an Al sample which has a flat absorption in the energy region of interest. The only structure is due do a "glitch", or anomalous reflection at $898 \mathrm{eV}$ for which we corrected using the Al reference. The energy scale was calibrated using the $\mathrm{Ni}_{2} \mathrm{p}_{3 / 2} . \mathrm{Cu} 2 \mathrm{p}_{3 / 2}$ and $\mathrm{Mg}$ $1 \mathrm{~s}$ edges and the corresponding XPS binding energies [11], as well as previously determined structures in the spectrum of Ce itself [12]. 
After pretreatment and/or sulphidation the specimens were exposed to air at room temperature for some weeks. They were then inserted in the vacuum system and baked $\left(150^{\circ} \mathrm{C}\right.$ for $\left.10 \mathrm{~h}\right)$ to reach ultra-high vacuum and remove lightly bound contamination from the surface).

\section{Results}

\subsection{Sulphidation tests}

Best and reproducible results were obtained for evenly distributed films on a smooth surface. In fig. 1 some typical thermogravimetric results are shown. it is observed that the test pieces with a Ce oxide layer (containing about $0.3 \mathrm{mg}$ ceria $/ \mathrm{cm}^{2}$ ) show by far the best resistance against sulphidation under the circumstances used in this study. Pretreating in argon leads to a significantly lower protective effect than pretreating in air.

Microscopic investigation after sulphidation was in complete agreement with the thermogravimetric results. The attack was severe only on uncoated specimens where it started in the form of sulphide nodules at random points on the surface [4].

It was shown with the electron microprobe that the product layer formed during sulphidation, which on coated specimens pretreated in air had a thickness of approximately $0.5 \mu \mathrm{m}$, consisted of a chromium-rich inner and an iron-rich outer layer. the distribution of the alloy constituents in these layers was comparable for coated and uncoated Incoloy $800 \mathrm{H}$. Electron microprobe

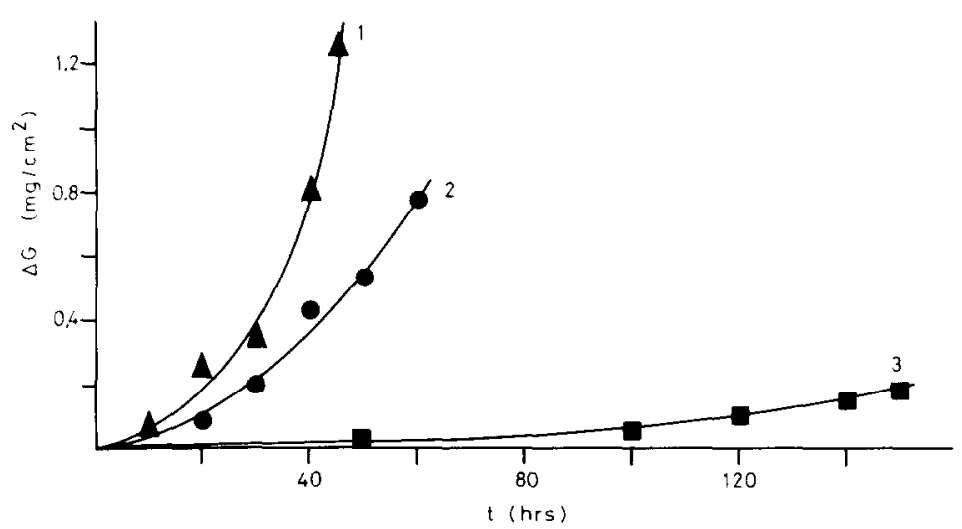

Fig. 1. Thermogravimetric results for Incoloy $800 \mathrm{H}$ in an $\mathrm{Ar} / \mathrm{H}_{2} / \mathrm{H}_{2} \mathrm{~S}$ atmosphere at $550^{\circ} \mathrm{C}$ after various pretreatments: (1) uncoated, pretreated in air at $850^{\circ} \mathrm{C} ;(2)$ coated with ceria. pretreated in Ar at $850^{\circ} \mathrm{C}:(3)$ coated with ceria, pretreated in air at $850^{\circ} \mathrm{C}$. 
analysis of the layer showed the cerium to be incorporated both in the inner and in the outer layer, similar to the findings of Bennett et al. [3] after oxidation in $\mathrm{CO}_{2}$. On the basis of the weight change by coating and by sulphidation it can be concluded that the layers contain a maximum of about $20 \%$ Ce oxide.

\subsection{X-ray absorption}

The normalized spectra recorded in the manner described above are reproduced in fig. 2. The spectrum shown in fig. $2 \mathrm{a}$. is that of the specimen pretreated in air and then exposed to $\mathrm{Ar} / \mathrm{H}_{2} / \mathrm{H}_{2} \mathrm{~S}$ for $160 \mathrm{~h}$ at $550^{\circ} \mathrm{C}$. The spectrum of the sample pretreated in argon and exposed to $\mathrm{Ar} / \mathrm{H}_{2} / \mathrm{H}_{2} \mathrm{~S}$ under the same conditions shows no significant structural differences, but the signal to noise ratio was poorer. This is consistent with a lower Ce concentration in the thicker sulphide film. These spectra are typical of those found for materials containing $C \mathrm{e}^{111}[6-8]$ and show structure due to the $3 \mathrm{~d}^{9} 4 \mathrm{f}^{2}$ multiplet. In principle about 20 lines should contribute appreciable weight to the

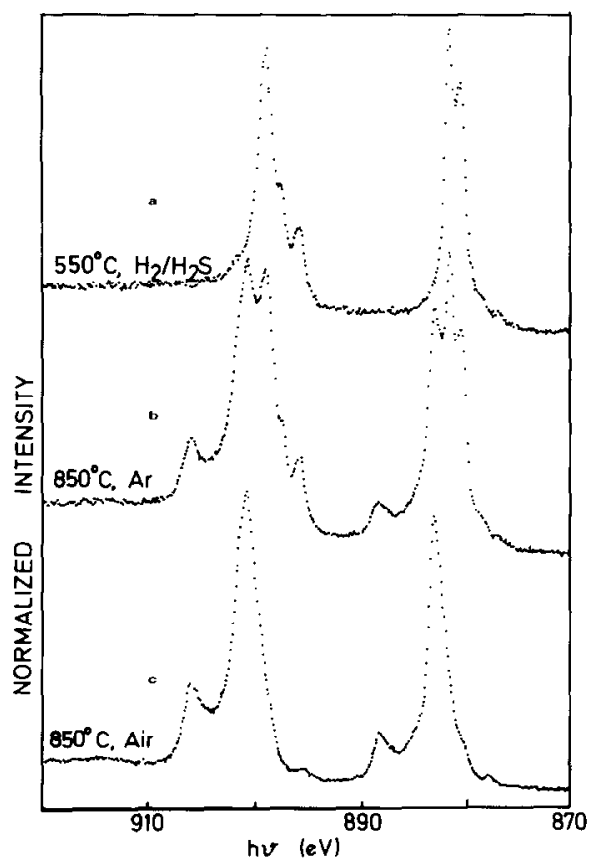

Fig. 2. XAS spectra of Incoloy $800 \mathrm{H}$ surfaces coated with ceria: (a) pretreated in air at $850^{\circ} \mathrm{C}$ and subsequently exposed at $550^{\circ} \mathrm{C}$ to an $\mathrm{Ar} / \mathrm{H}_{2} / \mathrm{H}_{2} \mathrm{~S}$ mixture for $160 \mathrm{~h}$; (b) pretreated in Ar at $850^{\circ} \mathrm{C}$; (c) pretreated in air at $850^{\circ} \mathrm{C}$. 
spectrum under dipole selection rules and seven or eight peaks are usually resolved. The eight found here are the same as in $\gamma$-Ce and many of its intermetallic compounds with one f-electron in the ground state.

The contrast between the above spectrum and that for a sample treated only in air at $850^{\circ} \mathrm{C}$ is great. Essentially none of the $\mathrm{Ce}^{\mathrm{III}}$ peaks are found, although weak intensity at about $881-882$ and $898 \mathrm{eV}$ may be due to residual $\mathrm{Ce}^{\text {III }}$ in the surface layer. The assignment of these peaks is difficult and must take into account hybridization between the $\mathrm{Ce} 4 \mathrm{f}$ and $\mathrm{O} 2 \mathrm{p}$ states in the $3 \mathrm{~d}^{9} 4 \mathrm{f}^{1}$ and $3 \mathrm{~d}^{9} 4 \mathrm{f}^{2}$ configurations as discussed by Fujimori [13]. The spectrum is not as simple as that found, for instance, in La [12] which also has local $3 \mathrm{~d}^{9} 4 \mathrm{f}^{1}$ final state configurations. Nevertheless, whilst these complications are related to the electronic structure of the $\mathrm{Ce}^{\mathrm{IV}}$, there can be no question that this spectrum is derived from $\mathrm{Ce}$ atoms which are chemically 4 -valent.

The spectrum of the sample treated at $850^{\circ} \mathrm{C}$ in argon can be reproduced by superimposing the spectra of the sample treated only in air and of the sulphidized sample in approximately the ratio $1: 1$. This means that both $\mathrm{Ce}^{1: !}$ and $\mathrm{Ce}^{\mathrm{IV}}$ are present in the surface layer analysed. Although we cannot say anything definitive about the distribution of $\mathrm{Ce}^{\mathrm{III}}$ and $\mathrm{Ce}^{\mathrm{IV}}$ or the composition through the whole cerium containing oxide layer, it is probable that it is mostly $C \mathrm{e}^{\mathrm{III}}$ with a little $\mathrm{Ce}^{\mathrm{IV}}$ in the surface layer.

\subsection{ESCA measurements}

Preliminary ESCA measurements of the air-pretreated coated specimen after sulphidation showed that the protective layer was $\mathrm{Cr}$-rich even at the gas-solid interface. Using Scofield's XPS cross-sections and peak intensities we estimated that the oxygen content exceeded that of sulphur even after the initial $30 \mathrm{~s}$ sputtering to remove superficial contamination. The sulphur content dropped off slowly as the layer was sputtered away. Somc Ce appeared from all depths in the protective layer but the XPS cerium peaks were too weak for detailed XPS studies of the chemical state of $\mathrm{Ce}$.

In the specimen pretreated in air but not sulphidized, the Ce peaks were stronger, indicating a higher Ce concentration.

\section{Discussion}

As shown by the thermogravimetric results reproduced in fig. 1 coating with cerium oxide is very promising for protecting stainless steel against sulphidizing environments. However, there are significant differences depending on whether the sintering heat treatment was performed in air or in argon. This is similar to earlier results of Bennett et al. [3], who found a favourable influence of pre-oxidation on the behaviour of cerium oxide coatings on a $20 / 25 / \mathrm{Nb}$ 
chromium-nickel steel. By contrast Ecer et al. [2] found a beneficial effect on the oxidation rate of $\mathrm{Ni}$ - and $\mathrm{Fe}$-base alloys when no preoxidation had been applied. Our results show that preoxidation, or at least pretreating in air after application of the coating, is essential for protection under sulphidizing conditions.

We now consider the mechanism of passivation of the Incoloy by the cerium oxide. As shown clearly by the ESCA (XPS) results the layer present on the surface is not a pure cerium oxide but a mixed oxide containing cerium in a distributed form. But XAS clearly shows that more $\mathrm{Ce}^{\mathrm{IV}}$ is present in the air-treated layer and it is attractive to link the protection to its presence. As indicated in the introduction the possible mechanisms of passivation include formation of a diffusion barrier or better adherence between the oxide containing $\mathrm{Ce}$ and the metal surface. Also deactivation of "active" corrosion areas on the metal may occur. The surface layer of both air and Ar pretreated cerium oxide layers are clearly reduced by the $\mathrm{H}_{2} / \mathrm{H}_{2} \mathrm{~S}$ containing gas. This must result in a major reorganization of the atoms of the overlayer. It seems improbable that the air-formed overlayer would remain impervious under these conditions, while the argon-treated layer does not. We thus discard the mechanism of passivation by diffusion barriers made impervious by the presence of cerium. This is supported by the ESCA measurements which indicate that by sulphidation the cerium content of the protective layer is decreased.

Because of the limited penetration depth of the X-ray absorption measurements it has probably not been possible to determine the state of the $\mathrm{Ce}$ throughout the whole layer.

$\mathrm{Ce}^{\mathrm{IV}}$ is unlikely to oxidize the steel surface. The heats of formation in $\mathrm{kJ}$ $\mathrm{mol}^{-1}$ at $300 \mathrm{~K}$ for some relevant oxides are: $\mathrm{CeO}_{2}=1090, \mathrm{Ce}_{2} \mathrm{O}_{3}=1790$, $\mathrm{FeO}=272, \mathrm{Fe}_{2} \mathrm{O}_{3}=824, \mathrm{Cr}_{2} \mathrm{O}_{3}=1160, \mathrm{NiO}=128$. Thus reduction of $\mathrm{CeO}_{2}$ by the alloy constituents is energetically unfavourable at room temperature. e.g.:

$$
\begin{array}{ll}
2 \mathrm{CeO}_{2}+\mathrm{Ni} \rightarrow \mathrm{Ce}_{2} \mathrm{O}_{3}+\mathrm{NiO}, & \Delta H=+128 \mathrm{~kJ} \mathrm{~mol}^{-1} ; \\
2 \mathrm{CeO}_{2}+\mathrm{Fe} \rightarrow \mathrm{Ce}_{2} \mathrm{O}_{3}+\mathrm{FeO}, & \Delta H=+118 \mathrm{~kJ} \mathrm{~mol}^{-1} ; \\
6 \mathrm{CeO}_{2}+2 \mathrm{Fe} \rightarrow 3 \mathrm{Ce}_{2} \mathrm{O}_{3}+\mathrm{Fe}_{2} \mathrm{O}_{3}, & \Delta H=+346 \mathrm{~kJ} \mathrm{~mol}^{-1} ; \\
6 \mathrm{CeO}_{2}+2 \mathrm{Cr} \rightarrow 3 \mathrm{Ce}_{2} \mathrm{O}_{3}+\mathrm{Cr}_{2} \mathrm{O}_{3}, & \Delta H=+10 \mathrm{~kJ} \mathrm{~mol}^{\prime}
\end{array}
$$

Such reactions are thus unlikely to be a strong factor, even at $550^{\circ} \mathrm{C}$.

\section{Concluding remarks}

In this study we have illustrated the potential of XAS at the $3 \mathrm{~d}$ edges to investigate protective layers of cerium oxides and the presence of $\mathrm{Ce}^{\mathrm{III}}$ or $\mathrm{Ce} \mathrm{e}^{\mathrm{IV}}$ 
therein. The extremely high sensitivity of XAS allows the discrimination between the chemical state of the atoms in the protective layer more easily than XPS. We feel that $\mathrm{X}$-ray absorption studies in the soft $\mathrm{X}$-ray region have further potential for this sort of investigation. In this particular case we were able to show that effective passivation of the metal investigated. Incoloy $800 \mathrm{H}$. could be correlated with the presence of an increased $\mathrm{Ce}^{\mathrm{IV}}$ concentration in the overlayer after pretreatment.

Our results lead to further questions such as the nature of the interface between the metal and the Ce containing oxide layer and the variation of the composition of this layer with depth. Also the distribution of oxygen and sulphur in the sulphidized layers must be known before it is possible to reach a full understanding of the mechanism of the protection. Studies concerning these factors could be attempted by combination of XPS (ESCA), X-ray absorption and sputter-profile methods.

Clearly the presence of cerium has a very positive effect on the behaviour of stainless steel under sulphidizing conditions. This opens several new channels for investigation. For instance one is not restricted to the use of coatings, small additions of cerium as an alloying constituent of the steel may provide a similar effect if heating in air causes surface segregation and oxidation to $\mathrm{Ce}^{\mathrm{IV}}$.

\section{Acknowledgements}

We are grateful to the Laboratoire pour l'Utilization due Rayonnement Electromagnétique (LURE) technical staff for their valuable aid and also the Groupe Anncaux du Laboratoire de l'Accélérateur Linćaire for their help. We also thank Magda Perik for help with the thermogravimetric measurements, M.A. de Jongh for his assistance in the microscopic observations, S. Mandziej for performing the electron microprobe analyses as well as G.A. Sawatzky for valuable discussions.

\section{References}

[1] A good general article on corrosion problems of the type considered here is:

J. Stringer, in: High Temperature Materials Corrosion in Coal Gasification Atmospheres. Ed. J.F. Norton (Elsevier, Amsterdam, 1984) p. 83.

Other useful articles can be found in:

D.B Meadowcroft and M.I. Manning, Eds., Corrosion Resistant Materials for Coal Conversion Systems (Applied Science Publishers, London, 1983);

Behaviour of High Temperature Alloys in Aggressive Environments, Proc. Intern. Conf. Petten, 1979 (Metals Society, London, 1980);

Proc. 9th Intern. Congr. on Metallic Corrosion, Toronto, June 1984 (National Research Council, Ottawa, 1984). 
[2] G.M. Ecer, R.B. Singh and G.H. Meier, Oxidation Metals 18 (I982) 55.

[3] M.J. Bennett, M.R. Houlton and J.B. Price. New Ceramic Coatings for High Temperature Gas Cooled Reactor Materials Protection, in: Proc. IAEA Specialists Meeting on High Temperature Materials for Application in Gas-Cooled Reactors (IAEA, Vienna, 1981) p. 7.

[4] A preliminary account of the thermogravinetuic results was presented by.

T. Fransen. M.A. de Jongh, M.M.A. Perik and P.J. Gellings, in: Proc. 9th Intern. Congr. on Metallic Corrosion. Toronto. Canada (National Research Council, Ottawa, 1984) Vol. 4, p. 311.

[5] These configurations are not complete; the $C$ e $5 d, 6 s$ and $O 2$ p electrons have been neglected. Also the labels $f^{0} . f^{1}$, and $f^{2}$ are approximate hecause hybridization can lead to non-integral f-counts [7-9].

[6] See. e.g. C. Bonnelle, R.C. Karnatak and J. Sugar, Phys. Rev. A9 (1974) 1920.

[7] J.C. Fuggle, F.U. Hillebrecht, J.-M. Esteva, R.C. Karnatak, O. Gunnarsion and K. Schönhammèr, Phys. Rev. B27 (1983) 4637

[8] J.-M. Esteva. R.C. Karnatak, J.C. Fuggle and G.A. Sawatzky, Phys. Rev. Letters 50 (198.3) 910.

[9] E. Wuilloud, B. Delley, W.-D. Schneider and Y. Baer, Phys. Rev. Letters 53 (1984) 202.

[10] M. Lemonnier, O. Collet. C. Depautex and D. Raoux, Nucl. Instr. Methods 152 (1978) 109.

[11] J.C. Fuggle and N. Mărtensson, J. Electron Spectrosc. Related Phenomena 21 (1980) 275.

[12] J.C. Fuggle, F.U. Hillebrecht, J.-M. Estevia, R.C. Karnatak, O. Gunnarsson and $K$ Schönhammer, Phys. Rev. B27 (1983) 4637.

[13] A. Fujimori, Phys. Rev. B28 (1983) 2281. 